\title{
Visual Test of Subparts per Billion-Level Mercuric Ion with a Gold Nanoparticle Probe after Preconcentration by Hollow Fiber Supported Liquid Membrane
}

\author{
Zhi-qiang Tan and Jing-fu Liu* \\ State Key Laboratory of Environmental Chemistry and Ecotoxicology, Research Center for Eco-Environmental \\ Sciences, Chinese Academy of Sciences, P.O. Box 2871, Beijing 100085, China
}

With the combination of the gold nanoparticle (AuNP)based visual test with hollow fiber supported liquid membrane (HFSLM) extraction, a highly sensitive and selective method was developed for field detection of mercuric ion $\left(\mathrm{Hg}^{2+}\right)$ in environmental waters. $\mathrm{Hg}^{2+}$ in water samples was extracted through HFSLM and trapped in the aqueous acceptor and then visually detected based on the red-to-blue color change of 3-mercaptopropionic acid-functionalized AuNP (MPAAuNP) probe. The highest extraction efficiency of $\mathbf{H g}^{2+}$ was obtained by using a $600 \mathrm{~mL}$ sample (pH 8.0, 2.0\% (w/v) $\mathrm{NaCl}$ ), $\sim 35 \mu \mathrm{L}$ of acceptor $(10 \mathrm{mM}$ of 2,6pyridinedicarboxylic acid, $\mathrm{pH}$ 4.0) filled in the lumen of a polypropylene hollow fiber tubing $(55 \mathrm{~cm}$ in length, $50 \mu \mathrm{m}$ wall thickness, $280 \mu \mathrm{m}$ inner diameter), a liquid membrane of $2.0 \%(\mathrm{w} / \mathrm{v})$ trioctycphosphine oxide in undecane, and a shaking rate of $250 \mathrm{rpm}$. The chromegenic reaction was conducted by incubating the mixture of MPA-AuNP stock solution (12 $\mu \mathrm{L}, 15 \mathrm{nM})$, Tris-borate buffer solution ( $18 \mu \mathrm{L}, 0.2 \mathrm{M}, \mathrm{pH} \mathrm{9.5)}$, and acceptor $(30 \mu \mathrm{L})$ at $30^{\circ} \mathrm{C}$ for $1 \mathrm{~h}$. The detection limit can be adjusted to $0.8 \mu \mathrm{g} / \mathrm{L} \mathrm{Hg}^{2+}$ (corresponding to an enrichment factor of $\sim 1000$ in the HFSLM) and $2.0 \mu \mathrm{g} / \mathrm{L} \mathrm{Hg}^{2+}$ (the U.S. Environmental Protection Agency limit of $\left[\mathrm{Hg}^{2+}\right]$ for drinkable water) by using extraction times of 3 and $1 \mathrm{~h}$, respectively. The proposed method is extremely specific for $\mathrm{Hg}^{2+}$ with tolerance to at least 1000-fold of other environmentally relevant heavy and transition metal ions and was successfully applied to detect $\mathbf{H g}^{2+}$ in a certified reference water sample, as well as real river, lake, and tap water samples.

Highly sensitive and selective determination of $\mathrm{Hg}^{2+}$ in water samples is one of the major topics in environmental analysis, due to the widespread contamination and the severely adverse effects on human health and the ecological system of $\mathrm{Hg}^{2+} \cdot{ }^{-3}$ Although instruments such as atomic absorption spectrometry (AAS),${ }^{4}$ atomic fluorescence spectrometry (AFS), ${ }^{5}$ and inductively coupled plasma-mass spectrometry (ICPMS) ${ }^{6}$ have high sensitivity and excellent selectivity for the $\mathrm{Hg}^{2+}$ analysis, they have seldom

* Corresponding author. E-mail: jfliu@rcees.ac.cn. Fax: +86-10-62849192. been used in field analysis because of their nonportability (bulky and heaviness of the instruments). In cases such as environmental pollution accidents, however, it is demanded to determine $\mathrm{Hg}^{2+}$ rapidly in fields. Recently, miniature $\mathrm{AAS}^{7}$ and $\mathrm{AFS}^{8}$ instruments have been developed for field analysis, but they are of limited practical use because of the sophisticated instrument system and the strict requirements for laboratory facilities and technical operators.

Visual test are among the most suitable approaches for field analysis of $\mathrm{Hg}^{2+}$ as it requires no special equipment..$^{9-11}$ Traditionally, these procedures are based on the color change of organic chromophores, ${ }^{12-17}$ which had the restriction of low sensitivity due to their relatively low extinction coefficients. To overcome this restriction, extensive efforts have been made and it was demonstrated that visual methods based on DNAzyme ${ }^{18}$ and Au nanoparticles (AuNPs) ${ }^{19-26}$ provided high sensitivity and selectivity for the detection of $\mathrm{Hg}^{2+}$. Recent studies showed that

(1) Nolan, E. M.; Lippard, S. J. Chem. Rev. 2008, 108, 3443-3480.

(2) Jiang, G. B.; Shi, J. B.; Feng, X. B. Environ. Sci. Technol. 2006, 40, 36723678 .

(3) Leermakers, M.; Baeyens, W.; Quevauviller, P.; Horvat, M. Trends Anal. Chem. 2005, 24, 383-393.

(4) Alp, O.; Ertaş, N. J. Anal. At. Spectrom. 2009, 24, 93-96.

(5) Yin, Y. G.; Liu, J. F.; He, B.; Gao, E. L.; Jiang, G. B. J. Anal. At. Spectrom. 2007, 22, 822-826.

(6) Wang, M.; Feng, W. Y.; Wang, H. J.; Zhang, Y.; Li, J.; Li, B.; Zhao, Y. L.; Chai, Z. F. J. Anal. At. Spectrom. 2008, 23, 1112-1116.

(7) Erxleben, H.; Ruzicka, J. Anal. Chem. 2005, 77, 5124-5128.

(8) Yu, Y. L.; Du, Z.; Wang, J. H. J. Anal. At. Spectrom. 2007, 22, 650-656.

(9) Veselova, I. A.; Shekhovtsova, T. N. Anal. Chim. Acta 1999, 392, 151158.

(10) Shi, G. Q.; Jiang, G. B. Anal. Sci. 2002, 18, 1215-1219.

(11) Palomares, E.; Vilar, R.; Durrant, J. R. Chem. Commun. 2004, 362-363.

(12) Choi, M. J.; Kim, M. Y.; Chang, S. K. Chem. Commun. 2001, 1664-1665.

(13) Tatay, S.; Gavina, P.; Coronado, E.; Palomares, E. Org. Lett. 2006, 8, 38573860.

(14) Fu, Y. Y.; Li, H. X.; Hu, W. P. Eur. J. Org. Chem. 2007, 245, 9-2463.

(15) Yuan, M. J.; Li, Y. L.; Li, J. B.; Li, C. H.; Liu, X. F.; Lv, J.; Xu, J. L.; Liu, H. B.; Wang, S.; Zhu, D. B. Org. Lett. 2007, 9, 2313-2316.

(16) Shunmugam, R.; Gabriel, G. J.; Smith, C. E.; Aamer, K. A.; Tew, G. N. Chem.-Eur. J. 2008, 14, 3904-3907.

(17) del Campo, O.; Carbayo, A.; Cuevas, J. V.; Munoz, A.; Garcia-Herbosa, G.; Moreno, D.; Ballesteros, E.; Basurto, S.; Gomez, T.; Torroba, T. Chem. Commun. 2008, 4576-4578.

(18) Li, T.; Li, B. L.; Wang, E. K.; Dong, S. J. Chem. Commun. 2009, 35513553.

(19) Huang, C. C.; Chang, H. T. Chem. Commun. 2007, 1215-1217.

(20) He, S. J.; Li, D.; Zhu, C. F.; Song, S. P.; Wang, L. H.; Long, Y. T.; Fan, C. H. Chem. Commun. 2008, 4885-4887.

(21) Xue, X. J.; Wang, F.; Liu, X. G. J. Am. Chem. Soc. 2008, 130, 3244-3245. 
by inhibiting the peroxidase-like DNAzyme function of a T-containing G-quadruplex DNA in the 3,3',5,5'tetramethylbenzidine- $\mathrm{H}_{2} \mathrm{O}_{2}$ reaction system, $\mathrm{Hg}^{2+}$ can be detected selectively at the $20 \mu \mathrm{g} / \mathrm{L}$ level with the naked eye. ${ }^{18}$ While the visual detection limits were above $120 \mu \mathrm{g} / \mathrm{L} \mathrm{Hg}^{2+}$ for most of the AuNP-based methods ${ }^{27}$ a new approach that enables detection of $5 \mu \mathrm{g} / \mathrm{L} \mathrm{Hg}^{2+}$ with the naked eye was developed by our group very recently. ${ }^{28}$ This novel method is based on the $\mathrm{Hg}^{2+}$ triggered cloud point extraction of $\sim 4 \mathrm{~nm}$-diameter mercaptopropionic acid and homocystine functionalized AuNPs into the colorless Triton X-114-rich phase. Nevertheless, all the currently available naked eye-based methods are unable to meet the maximum allowable level of $\mathrm{Hg}^{2+}$ in drinkable water $\left(2.0 \mu \mathrm{g} / \mathrm{L} \mathrm{Hg}^{2+}\right)$ defined by the U.S. Environmental Protection Agency (EPA), and efforts aimed at developing more sensitive probes to reach the visual detection limit of $2.0 \mu \mathrm{g} / \mathrm{L} \mathrm{Hg}^{2+}$ are of great interest.

An alternative to meet the low detection limit of $\mathrm{Hg}^{2+}$ is coupling an efficient preconcentration procedure with a readily available visual test method. However, very limited studies on this approach have been reported, ${ }^{29}$ mainly due to the lack of suitable preconcentration techniques that can be conveniently coupled with a visual test procedure. Supported liquid membrane (SLM) ${ }^{30-33}$ extraction that has been successfully applied to preconcentrate some metals should be suited for this purpose. Both flat sheet- ${ }^{34,35}$ and hollow fiber- ${ }^{36-41}$ based SLM (HFSLM) were demonstrated to be capable of selectively concentrating some metal ions into an aqueous solution (usually $<1 \mathrm{~mL}$ ) with enrichment factors up to $3000 .^{36,40}$ The HFSLM technique is especially compatible with visual test methods due to its extremely high ratio of sample to acceptor, which enables the concentration

(22) Xu, X. W.; Wang, J.; Jiao, K.; Yang, X. R. Biosens. Bioelectron. 2009, 24, 3153-3158

(23) Wang, H.; Wang, Y. X.; Jin, J. Y.; Yang, R. H. Anal. Chem. 2008, 80, 90219028.

(24) Yu, C. J.; Tseng, W. L. Langmuir 2008, 24, 12717-12722.

(25) Li, D.; Wieckowska, A.; Willner, I. Angew. Chem., Int. Ed. 2008, 47, 39273931.

(26) Darbha, G. K.; Singh, A. K.; Rai, U. S.; Yu, E.; Yu, H. T.; Ray, P. C. J. Am. Chem. Soc. 2008, 130, 8038-8043.

(27) Lee, J. S.; Han, M. S.; Mirkin, C. A. Angew. Chem., Int. Ed. 2007, 46, 40934096.

(28) Tan, Z. Q.; Liu, J. F.; Liu, R.; Yin, Y. G.; Jiang, G. B. Chem. Commun. 2009, 7030-7032.

(29) Götzl, A.; Riepe, W. Talanta 2001, 54, 821-827.

(30) Jönsson, J. Å.; Mathiasson, L. Trends Anal. Chem. 1999, 18, 318-325.

(31) de Gyves, J.; de San Miguel, E. R. Ind. Eng. Chem. Res. 1999, 38, 21822202.

(32) Rasmussen, K. E.; Pedersen-Bjergaard, S. Trends Anal. Chem. 2004, 23, $1-10$.

(33) Lee, J. Y.; Lee, H. K.; Rasmussen, K. E.; Pedersen-Bjergaard, S. Anal. Chim. Acta 2008, 624, 253-268.

(34) Papantoni, M.; Djane, N. K.; Ndung'u, K.; Jönsson, J. Å.; Mathiasson, L. Analyst 1995, 1471-1477.

(35) Romero, R.; Jönsson, J. Å. Anal. Bional. Chem. 2005, 381, 1452-1459.

(36) Parthasarathy, N.; Pelletier, M.; Buffle, J. Anal. Chim. Acta 1997, 350, 183-195.

(37) Parthasarathy, N.; Pelletier, M.; Buffle, J. J. Chromatogr., A 2004, 1025, 33-40.

(38) Romero, R.; Liu, J. F.; Mayer, P.; Jönsson, J. Å. Anal. Chem. 2005, 77, 7605-7611.

(39) Pena-Pereira, F.; Lavilla, I.; Bendicho, C. Spectrochim. Acta, Part B 2009, $64,1-15$.

(40) Peng, J. F.; Liu, R.; Liu, J. F.; He, B.; Hu, X. L.; Jiang, G. B. Spectrochim. Acta, Part B 2007, 62, 499-503.

(41) de San Miguel, E. R.; Liu, J. F.; Mayer, P.; Jönsson, J. Å. Solv. Extract. Ion Exch. 2008, 26, 602-623. of analytes from several hundred milliliter water samples to several microliter aqueous acceptors in a short time. Besides, HFSLM has the advantages of high robustness and reliability, and low cost.

In this study, we combined HFSLM with the AuNP-based visual test for highly sensitive and selective detection of $\mathrm{Hg}^{2+}$ in environmental waters. $\mathrm{Hg}^{2+}$ transports through the HFSLM (undecane with trioctycphosphine oxide, TOPO, as a mobile carrier) and was trapped in the acceptor by 2,6-pyridinedicarboxylic acid (PDCA). Then the acceptor with the enriched $\mathrm{Hg}^{2+}$ was mixed with 3-mercaptopropionic acid-functionalized AuNPs (MPA-AuNPs), and the $\mathrm{Hg}^{2+}$ concentration was detected based on the red-to-blue color change of the MPA-AuNPs.

\section{EXPERIMENTAL SECTION}

Chemicals and Materials. $\mathrm{Hg}^{2+}$ standard solutions were prepared by serial dilution of a stock standard solution of 100 $\mu \mathrm{g} / \mathrm{mL} \mathrm{Hg}^{2+}$ (GBW(E)080124, National Research Center for Certified Reference Materials, China). TOPO was obtained from Strem (Newburyport, MA). $n$-Undecane and PDCA were purchased from Alfa (Aesar). 3-Mercaptopropionic acid (MPA) was obtained from Acros Organics (Belgium). Hydrogen tetrachloroaurate, sodium citrate, and other chemicals were obtained from Sinopharm Chemical Reagent Co. (Beijing, China). All the chemicals used were of analytical grade or better and were used without further purification. The certified reference water sample containing $10 \mu \mathrm{g} / \mathrm{L} \mathrm{Hg}^{2+}$ (GBW08603) was purchased from the National Research Center for Certified Reference Materials (Beijing, China). Ultrapure water (18.3 $\mathrm{M} \Omega$ ) produced with a Milli-Q Gradient system (Millipore, Bedford) was used throughout. The 50/280 Accurel PP polypropylene hollow fiber tubing ( $50 \mu \mathrm{m}$ wall thickness, 280 $\mu \mathrm{m}$ inner diameter, $0.1 \mu \mathrm{m}$ pore size) was obtained from Membrana (Wuppertal, Germany).

Preparation and Modification of AuNPs. AuNPs $(\sim 13 \mathrm{~nm})$ were synthesized by reduction of $\mathrm{HAuCl}_{4}$ with sodium citrate. ${ }^{25}$ Briefly, after the $\mathrm{HAuCl}_{4}$ solution $(250 \mathrm{~mL}, 1 \mathrm{mM})$ was heated to keep boiling for $30 \mathrm{~min}, 25 \mathrm{~mL}$ of trisodium citrate solution $(38.8 \mathrm{mM})$ was added into the boiling solution as quickly as possible. When the color of the reaction solution changed from light yellow to deep red, the mixture was heated for another $30 \mathrm{~min}$. Then, the obtained AuNP solution was cooled to room temperature with stirring. TEM (H-7500, Hitachi, Japan) analysis showed the obtained AuNPs have an average size of $13 \mathrm{~nm}$ (Figure S1 in the Supporting Information). The particle concentration of AuNPs, calculated by Beer's law, was about 15 $\mathrm{nM} \cdot{ }^{24}$ For modification, into $10 \mathrm{~mL}$ of the above obtained AuNP solution was added $10 \mu \mathrm{L}$ of MPA (10 mM) under stirring and the mixture was further stirred for $2 \mathrm{~h}$ at room temperature. This MPA modified AuNP (MPA-AuNP) stock solution can be stored for at least 30 days in a refrigerator $\left(4^{\circ} \mathrm{C}\right)$ and 3 days at room temperature.

Preconcentration of $\mathbf{H g}^{2+}$ by HFSLM. The extraction procedure was modified from our previous report. ${ }^{42}$ In brief, hollow fiber pieces of approximately $55 \mathrm{~cm}$ in length were flushed and filled with water and immersed into the organic membrane liquid $(2.0 \%(\mathrm{w} / \mathrm{v})$ TOPO in undecane) for $\sim 5 \mathrm{~min}$. Then, the lumen of the fiber was flushed slowly with the acceptor solution

(42) Liu, J. F.; Jönsson, J. Å.; Mayer, P. Anal. Chem. 2005, 77, 4800-4809. 
(10 mM PDCA prepared in $10 \mathrm{mM}$ phosphate-citric acid buffer, $\mathrm{pH}$ 4.0), held in a BD Micro-Fine Syringe (BD Consumer Healthcare, NJ 07417), to remove any organic solvent and air bubbles. After the lumen was completely filled with the acceptor, the two ends of the fiber were folded and sealed with a strip of aluminum foil. This prepared hollow fiber extraction device was immersed into the $600 \mathrm{~mL}$ sample solution, which was preadjusted to containing $4.0 \mathrm{mM}$ Tris- $\mathrm{HCl}$ buffer $(\mathrm{pH} 8.0)$ and $2.0 \%(\mathrm{w} / \mathrm{v})$ $\mathrm{NaCl}$. The hollow fiber extraction device was collected after shaking at $250 \mathrm{rpm}$ for $1 \mathrm{~h}$, and the acceptor phase was flushed out by air with a BD Micro-Fine Syringe into a polyethylene vial $(200 \mu \mathrm{L})$ for the following chromogenic reaction.

Visual/Colorimetric Detection of $\mathrm{Hg}^{2+}$ with MPA-AuNPs as a Probe. Into a $200 \mu \mathrm{L}$ polyethylene vial or a well of the 384 well-plate was added $12 \mu \mathrm{L}$ of MPA-AuNP stock solution ( $15 \mathrm{nM})$, $18 \mu \mathrm{L}$ of Tris-borate buffer solution (0.2 M, pH 9.5), and $30 \mu \mathrm{L}$ of acceptor with the extracted $\mathrm{Hg}^{2+}$. The mixture was incubated at $30{ }^{\circ} \mathrm{C}$ for $1 \mathrm{~h}$ before visual or colorimetric detection. A multimode microplate spectrophotometer (Varioscan Flash, Thermo) with a 384 well-plate was employed for recording the absorbance in the range of 500-700 $\mathrm{nm}$ during the optimization of the test conditions.

Sample Collection and Preparation. Lake water was collected from Taihu Lake (Jiangsu, China). River water was obtained from the upriver of Taihu Lake. Tap water was collected in our laboratory after flow of about 5 min. Before extraction, the acidic certified reference water sample (GBW08603) was adjusted to about $\mathrm{pH} 5$ with $\mathrm{NaOH}(1 \mathrm{M})$ and the surface water samples were filtered through $0.25 \mu \mathrm{m}$ micropore membranes.

\section{RESULTS AND DISCUSSION}

Since the maximum absorbance wavelength $\left(\lambda_{\max }\right)$ of the MPAAuNP solution shifted from 520 to $650 \mathrm{~nm}$ in the presence of $\mathrm{Hg}^{2+}$ (Figure S1 in the Supporting Information), the ratio of absorbance at $650 \mathrm{~nm}$ to that at $520 \mathrm{~nm}\left(A_{650} / A_{520}\right)$ increased with $\mathrm{Hg}^{2+}$ concentration and was selected as a response variable for the optimization of the extraction and chromogenic reaction.

Optimization of the HFSLM Extraction. In this present study, $\mathrm{Hg}^{2+}$ transported through the SLM (with TOPO as a mobile carrier) and was stripped in the acceptor by PDCA. Specifically, the cotransport of $\mathrm{Hg}^{2+}$ in HFSLM occurs by (i) $\mathrm{Hg}^{2+}$ and anion $\mathrm{X}^{-}$(mainly $\mathrm{OH}^{-}$and $\mathrm{Cl}^{-}$) in the sample solution diffuses to the donor-membrane interface and associates with TOPO to form the complex $\left[\mathrm{HgX}_{2} \cdot 2 \mathrm{TOPO}\right]$ through a solvating reaction; (ii) $\left[\mathrm{HgX}_{2} \cdot 2 \mathrm{TOPO}\right]$ then diffuses through the membrane toward the membrane-acceptor interface where the exchange reaction with PDCA occurs to form the new complexes $\left[\mathrm{Hg}(\mathrm{PDCA})_{n}\right](n=1-2)$; (iii) $\left[\mathrm{Hg}(\mathrm{PDCA})_{n}\right]$ was trapped in the acceptor due to its higher stability constant than $\mathrm{HgX}_{2}$, and TOPO diffuses back to the donor-membrane interface for repeating the process ${ }^{43-45}$

$$
\begin{array}{r}
\mathrm{Hg}^{2+}(\mathrm{aq})+2 \mathrm{X}^{-}(\mathrm{aq})+2 \mathrm{TOPO}(\mathrm{org})= \\
{\left[\mathrm{HgX}_{2} \cdot 2 \mathrm{TOPO}\right](\mathrm{org})}
\end{array}
$$

(43) Sato, T.; Nakamura, T. Hydrometallurgy 1980, 6, 3-12.

(44) Meera, R.; Francis, T.; Reddy, M. L. P. Hydrometallurgy 2001, 61, 97-103.

(45) Norkus, E.; Stalnioniene, I.; Crans, D. C. Heteroat. Chem. 2003, 14, 625632.
$\left[\mathrm{HgX}_{2} \cdot 2 \mathrm{TOPO}\right]($ org $)+n \mathrm{PDCA}(\mathrm{aq})=\left[\mathrm{Hg}(\mathrm{PDCA})_{n}\right](\mathrm{aq})+$

$$
2 \mathrm{X}^{-}(\mathrm{aq})+2 \mathrm{TOPO} \text { (org) }
$$

in which (aq) represents the aqueous phase, and (org) represents the organic liquid membrane phase.

Experiments were conducted to optimize the HFSLM conditions, such as the $\mathrm{pH}$ and salinity of the donor (sample), TOPO carrier concentration in the membrane liquid, $\mathrm{pH}$ and PDCA concentration of the acceptor, shaking rate, and extraction time. All the optimizations were conducted with $10 \mu \mathrm{g} / \mathrm{L} \mathrm{Hg}^{2+}$ standard solutions except that the $2.0 \mu \mathrm{g} / \mathrm{L} \mathrm{Hg}^{2+}$ standard solutions were used in the optimization of the sample volume. The chromogenic reaction was conducted in $0.05 \mathrm{M}$ Tris-borate buffer solution (pH 9.5), with $3 \mathrm{nM}$ MPA-AuNPs as the chromogenic reagent and an incubation time of $1 \mathrm{~h}$ at room temperature.

Donor $\mathrm{pH}$. The influence of sample $\mathrm{pH}$ on the extraction efficiency was studied by using $50 \mathrm{~mL}$ of $\mathrm{Hg}^{2+}$ standard solutions that were prepared in $4.0 \mathrm{mM}$ Tris-HCl buffer solutions with $\mathrm{pH}$ 4.0-9.0. Results illustrated in Figure 1 indicated that markedly higher $A_{650} / A_{520}$ values were obtained when the samples were extracted at alkaline conditions ( $\mathrm{pH}$ 7.0-9.0). This was ascribed to the markedly high complex constant of $\mathrm{Hg}^{2+}$ toward $\mathrm{OH}^{-}$in comparison to $\mathrm{Cl}^{-}$, i.e., the alkaline donor is helpful for the formation of neutralized $\mathrm{Hg}(\mathrm{OH})_{2}$, which enhances the preconcentration of $\mathrm{Hg}^{2+}$ in the acceptor. The slight increase of acceptor $\mathrm{pH}$ after extraction (Table $\mathrm{S} 1$ in the Supporting Information) also indicates that $\mathrm{Hg}^{2+}$ is transported through the liquid membrane in the form of $\mathrm{Hg}(\mathrm{OH})_{2}$. In the subsequent experiments, samples were adjusted to $\mathrm{pH}$ 8.0.

Donor Salinity. The effect of salinity was studied by using $\mathrm{NaCl}$ and $\mathrm{NaNO}_{3}$, respectively. As shown in Figure 1, the value of $A_{650} / A_{520}$ increased with the $\mathrm{NaCl}$ concentration up to $1.0 \%$ $(\mathrm{w} / \mathrm{v})$ and then flattened out. The enhancement of extraction efficiency in the presence of $\mathrm{NaCl}$ can be ascribed to two factors, namely, the increased partitioning of analytes into the

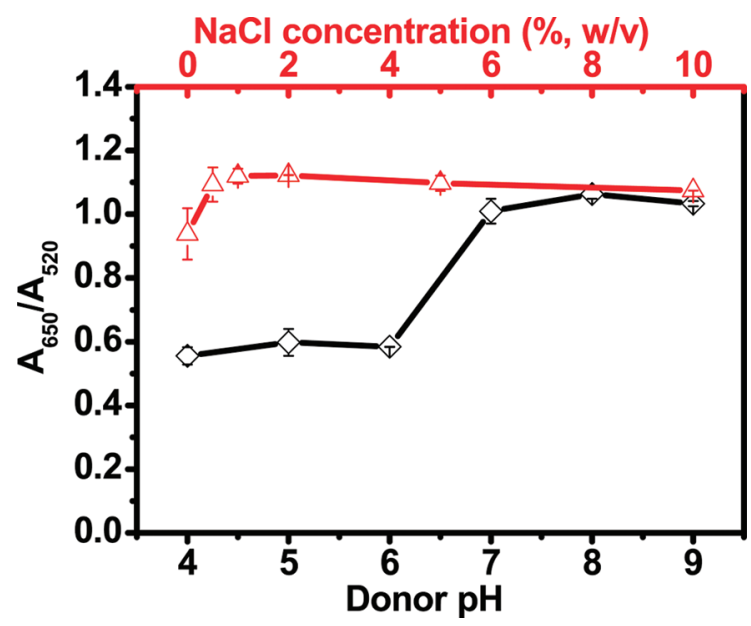

Figure 1. Effect of donor $\mathrm{pH}$ and salinity on the extraction efficiency of $\mathrm{Hg}^{2+}$ represented by $A_{650} / A_{520}$. Donor, $50 \mathrm{~mL}$ of $10 \mu \mathrm{g} / \mathrm{L} \mathrm{Hg}^{2+}$; liquid membrane, $1.0 \%(\mathrm{w} / \mathrm{v})$ TOPO dissolved in $n$-undecane; acceptor, 1.0 mM PDCA aqueous solution, fully filled in the lumen of a hollow fiber tubing (55 cm in length); extraction time and shaking rate, $3 \mathrm{~h}$ at 250 rpm. 


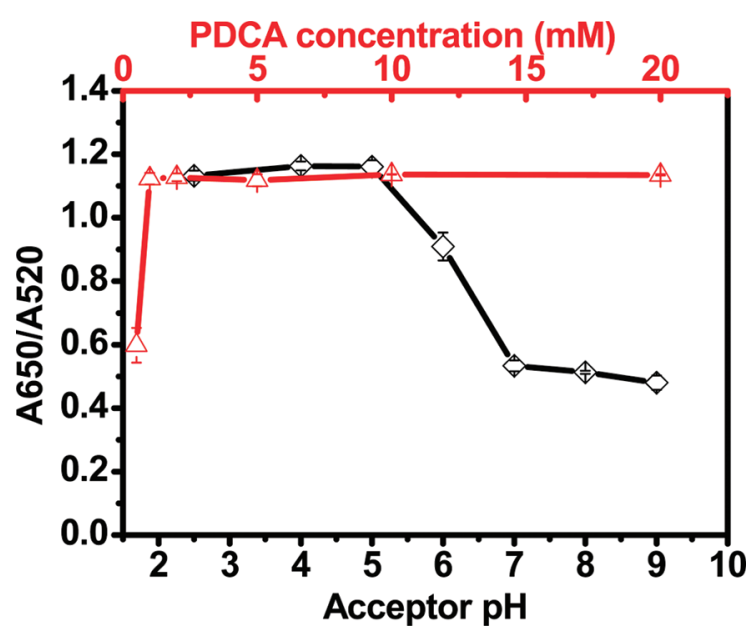

Figure 2. Effect of $\mathrm{pH}$ and PDCA concentration of the acceptor on the extraction efficiency of $\mathrm{Hg}^{2+}$ represented by $A_{650} / A_{520}$. Donor, 50 $\mathrm{mL}$ of solution containing $10 \mu \mathrm{g} / \mathrm{L} \mathrm{Hg}^{2+}, 4.0 \mathrm{mM}$ Tris- $\mathrm{HCl}$ buffer solution ( $\mathrm{pH} 8.0$ ), and $2.0 \%(\mathrm{w} / \mathrm{v}) \mathrm{NaCl}$; liquid membrane, $2.0 \%(\mathrm{w} / \mathrm{v})$ TOPO dissolved in $n$-undecane; acceptor, solutions of PDCA or mixture of PDCA and buffer fully filled in the lumen of a hollow fiber tubing (55 cm in length); extraction time and shaking rate, $3 \mathrm{~h}$ at 250 rpm.

liquid membrane ${ }^{46}$ due to the salt-out effect or the enhanced formation of the $\mathrm{HgCl}_{2}$ complex due to the increased $\mathrm{Cl}^{-}$ concentration. Since a similar result was obtained by replacing $\mathrm{NaCl}$ with $\mathrm{NaNO}_{3}$ (data not shown), the contribution of the latter factor was negligible.

Membrane Liquid. Both undecane and dihexyl ether were tested as the organic solvent for the preparation of the liquid membrane, and undecane was adopted as it exhibited a higher extraction efficiency and membrane stability. TOPO was added into the membrane liquid as a carrier to transport $\mathrm{Hg}^{2+}$ from the donor to the acceptor. The TOPO concentration in undecane was optimized in the range of $0.5-10 \%(\mathrm{w} / \mathrm{v})$, and it was found that the $A_{650} / A_{520}$ value increased with an increase of TOPO concentration from $0.5 \%$ to $2.0 \%$ and then kept constant with the further increase of the TOPO concentration (Figure S2 in the Supporting Information). Consequently, 2.0\% TOPO was adopted in subsequent studies.

Acceptor. PDCA was added into the acceptor to selectively trap $\mathrm{Hg}^{2+}$ due to its markedly large stability constant with $\mathrm{Hg}^{2+}$ in comparison to other metal ions such as $\mathrm{Pb}^{2+}$ and $\mathrm{Cd}^{2+} .47$ The effect of PDCA concentration on the extraction efficiency was shown in Figure 2, which indicates that the $A_{650} / A_{520}$ value increased sharply with PDCA concentration up to $1 \mathrm{mM}$ and then was almost kept constant. In the following studies, $10 \mathrm{mM}$ PDCA was adopted as optimum to ensure sufficient PDCA for trapping a high concentration of $\mathrm{Hg}^{2+}$. PDCA is a weak organic acid that releases $\mathrm{H}^{+}$in complexing with $\mathrm{Hg}^{2+}$. Therefore, it is of importance to optimize the acceptor $\mathrm{pH}$ to obtain a high enrichment of $\mathrm{Hg}^{2+}$. Figure 2 indicates that the enrichment of $\mathrm{Hg}^{2+}$ in the acceptor is kept high and constant at $\mathrm{pH} 2.5-5.0$ and reduced significantly with the increase of $\mathrm{pH}$ up to 7.0 and then gradually in the range of $\mathrm{pH}$ 7.0-9.0. This variation pattern can be explained by the $\mathrm{pH}$ dependent deprotonization of

(46) Cukrowska, W.; Chimuka, L.; Nsengimana, H.; Kwaramba, V. Anal. Chem. Acta 2004, 523, 141-147.

(47) Li, T.; Dong, S. J.; Wang, E. K. Anal. Chem. 2009, 81, 2144-2149.

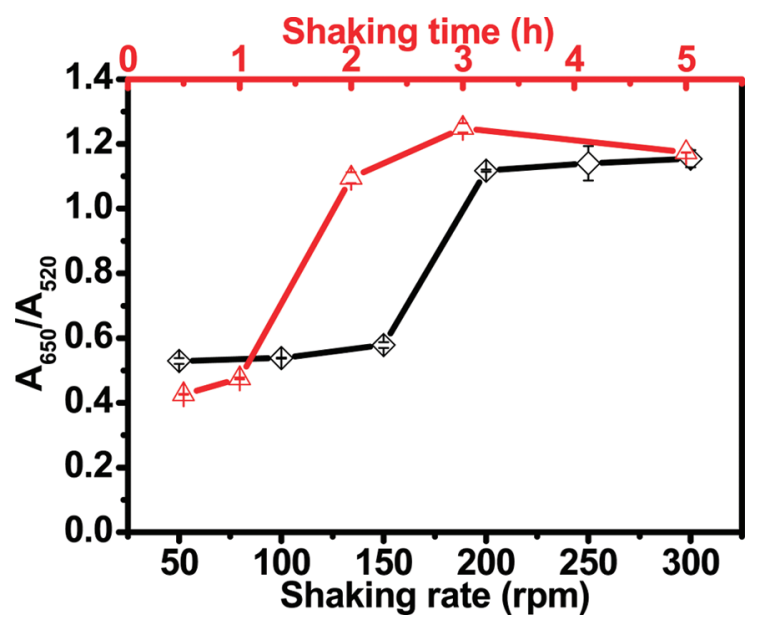

Figure 3. Effect of shaking rate and time on the extraction efficiency of $\mathrm{Hg}^{2+}$ represented by $A_{650} / A_{520}$. Donor, $50 \mathrm{~mL}$ of solution containing $10 \mu \mathrm{g} / \mathrm{L} \mathrm{Hg}^{2+}, 4.0 \mathrm{mM}$ Tris- $\mathrm{HCl}$ buffer solution ( $\mathrm{pH} 8.0$ ), and $2.0 \%$ $(\mathrm{w} / \mathrm{v}) \mathrm{NaCl}$; liquid membrane, $2.0 \%$ (w/v) TOPO dissolved in $n-$ undecane; acceptor, $10 \mathrm{mM}$ PDCA in $10 \mathrm{mM}$ sodium phosphatecitric acid buffer solution ( $\mathrm{pH} 4.0)$, fully filled in the lumen of a hollow fiber tubing (55 $\mathrm{cm}$ in length).

PDCA, which has acid dissociation constants of $\mathrm{p} K_{\mathrm{a} 1} 2.2$ and $\mathrm{p} K_{\mathrm{a} 2} 4.6 .{ }^{45}$ At $\mathrm{pH}$ 2.5-5.0, PDCA dissociates one proton to form $\mathrm{PDCA}^{-}$, which might favor the formation and trapping of charged complex $[\mathrm{Hg}(\mathrm{PDCA})]^{+}$in the acceptor. At $\mathrm{pH}>5$, however, $\mathrm{PDCA}^{-}$is further deprotonized to form $\mathrm{PDCA}^{2-}$ which could favor the formation of the neutralized complex [Hg(PDCA) ]. [Hg(PDCA)] can transport through the liquid membrane into the donor and thus leads to the reduced trapping of $\mathrm{Hg}$ in the acceptor. As the proton in the acceptor was neutralized by the $\mathrm{OH}^{-}$released from $\mathrm{Hg}(\mathrm{OH})_{2}$, it is of importance to add a buffer solution to maintain the optimum $\mathrm{pH}$ of the acceptor. Experiments showed that the variation of sodium phosphate-citric acid buffer concentration in the range of 1.0-20 mM caused no variation of the enrichment of $\mathrm{Hg}^{2+}$. Considering the high concentration of buffer might affect the following chromogenic reaction by AuNP probes, $10 \mathrm{mM}$ buffer ( $\mathrm{pH} 4.0)$ was adopted in the subsequent studies.

Shaking Rate and Time. The rate-limiting step in SLM of metals is either the uptake or release of metal ions at the membrane/ aqueous solution interface or the diffusion of the metal-carrier complex across the membrane. ${ }^{48}$ Agitation such as shaking can improve the diffusion rate and thus the extraction efficiency in cases that diffusion of analytes through the aqueous diffusion layer is the rate limiting process. In this present study, the effect of agitation was studied by increasing the shaking rate from 50 to $300 \mathrm{rpm}$, and higher extraction efficiency was obtained when the shaking rate increased to $200-300 \mathrm{rpm}$ (Figure 3 ). With the use of $250 \mathrm{rpm}$ as an optimum shaking rate, the effect of extraction time was studied in the range of $0.5-5 \mathrm{~h}$. Results shown in Figure 3 indicate that the highest extraction efficiency was obtained at $3 \mathrm{~h}$. The slight decrease of extraction efficiency at over $3 \mathrm{~h}$ might be attributed to the transportation of PDCA or neutralized forms of the Hg-PDCA complexes through the liquid membrane into the donor, which reduced the trapped $\mathrm{Hg}^{2+}$ in the acceptor.

(48) Guyon, F.; Parthasarathy, N.; Buffle, J. Anal. Chem. 1999, 71, 819-826. 


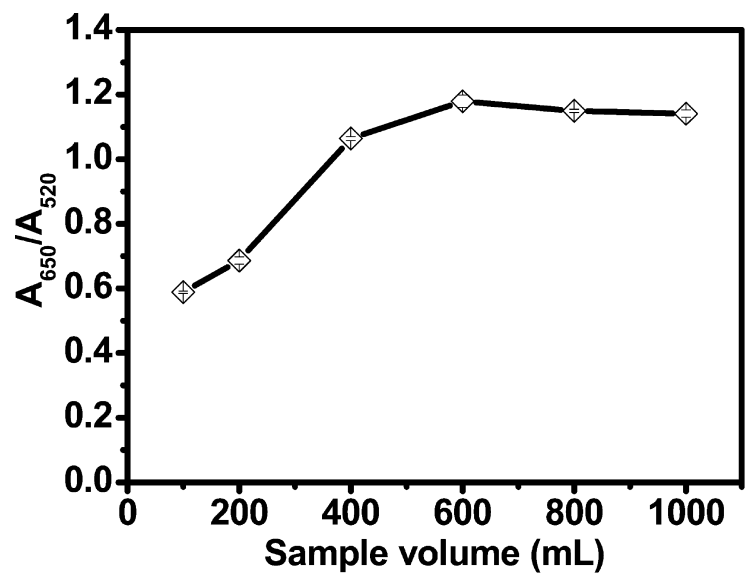

Figure 4. Effect of sample volume on the extraction efficiency of $\mathrm{Hg}^{2+}$ represented by $A_{650} / A_{520}$. Donor, solutions containing $2.0 \mu \mathrm{g} / \mathrm{L}$ $\mathrm{Hg}^{2+}, 4.0 \mathrm{mM}$ Tris-HCl buffer solution ( $\left.\mathrm{pH} 8.0\right)$, and $2.0 \%(\mathrm{w} / \mathrm{v}) \mathrm{NaCl}$; liquid membrane, $2.0 \%(\mathrm{w} / \mathrm{v})$ TOPO dissolved in $n$-undecane; acceptor, $10 \mathrm{mM}$ PDCA in $10 \mathrm{mM}$ sodium phosphate-citric acid buffer solution ( $\mathrm{pH} 4.0$ ), fully filled in the lumen of a hollow fiber tubing (55 $\mathrm{cm}$ in length); extraction time and shaking rate, $3 \mathrm{~h}$ at $250 \mathrm{rpm}$.

Sample and Acceptor Volume. In this proposed procedure, the detection sensitivity is dependent on the total amount of $\mathrm{Hg}^{2+}$ trapped by HFSLM. Therefore, a long hollow fiber membrane is helpful for obtaining high sensitivity and repeatability if the sample volume is sufficiently large. Experiments showed that a $55 \mathrm{~cm}$ long hollow fiber, with an acceptor volume of $\sim 35 \mu \mathrm{L}$, provided sufficiently high repeatability and was adopted in this study. Bear in mind the maximum allowable level of $\mathrm{Hg}^{2+}$ in drinkable water by EPA is $2.0 \mu \mathrm{g} / \mathrm{L}$; the effect of sample volume was studied by using $2.0 \mu \mathrm{g} / \mathrm{L} \mathrm{Hg}^{2+}$ sample solutions. The result shown in Figure 4 reveals that the $A_{650} / A_{520}$ value increased with sample volume up to $600 \mathrm{~mL}$ and then levels off. Consequently, the $600 \mathrm{~mL}$ sample that provided an enrichment
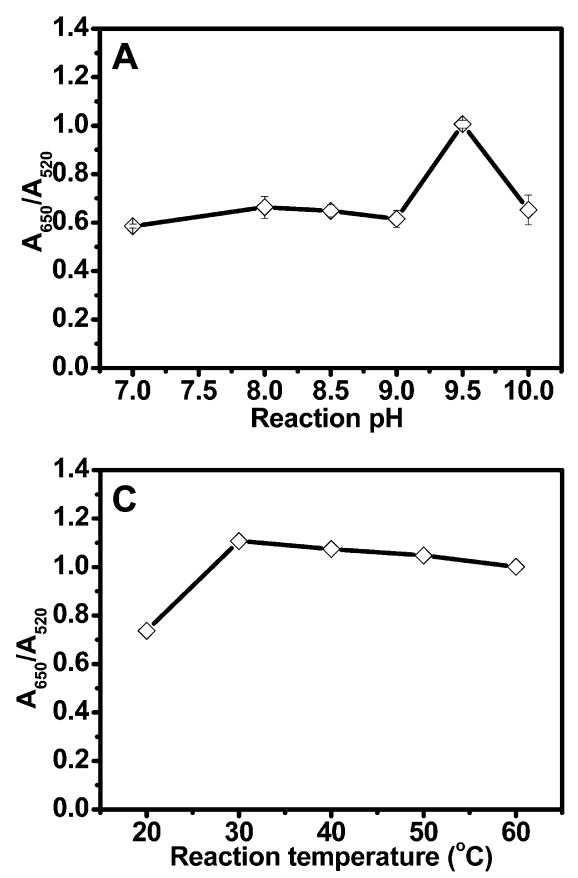

factor of 1000 was recommended for high sensitivity. In cases where low sensitivity is acceptable, smaller sample volumes might be adopted.

Optimization of the Chromogenic Reaction. Under the above optimized HFSLM conditions, parameters that might affect the aggregation-induced color change of MPA-AuNPs by $\mathrm{Hg}^{2+}$ were optimized in detail to improve the method sensitivity.

Buffer $p H$ and Composition. It was reported that the $\mathrm{pH}$ value and the buffer composition play a significant role in controlling the color changing of MPA-AuNPs by $\mathrm{Hg}^{2+}$, and Tris-borate buffer provided higher sensitivity in comparison to other buffers like Tris- $\mathrm{HCl}$ and borate- $\mathrm{NaOH}$ at the same $\mathrm{pH} .{ }^{19}$ Therefore, in this present study the effect of $\mathrm{pH}$ was evaluated by adding $10 \mathrm{mM}$ Tris-borate buffer with $\mathrm{pH}$ values of 7.0, 8.0, 8.5, 9.0, 9.5, and 10.0, respectively. Results shown in Figure 5A indicate that the highest $A_{650} / A_{520}$ value was obtained at $\mathrm{pH} 9.5$, which was adopted in the following work. In addition, the effect of buffer concentration in the colorimetric detection mixture was investigated by mixing $25 \mu \mathrm{L}$ of Tris-borate buffer solution with MPA-AuNP stock solution ( $5 \mu \mathrm{L}, 15 \mathrm{nM})$ and acceptor $(30 \mu \mathrm{L})$, and no distinct difference was observed when the initial concentration of the Tris-borate buffer solution was in the range of 0.02-0.2 M. Consequently, Tris-borate buffer solution with an initial concentration of $0.2 \mathrm{M}$ and $\mathrm{pH} 9.5$ was used as the optimum.

MPA-AuNP Concentration. The sensitivity of a colormetric method depends strongly on the chromogenic agent. Insufficient MPA-AuNPs gives rise to incomplete reaction with $\mathrm{Hg}^{2+}$ and thus low sensitivity, while over concentrated MPA-AuNPs also results in low sensitivity due to the high blank absorbance. The effect of MPA-AuNP concentration (0.75-4.5 nM) was evaluated with a constant $\mathrm{Hg}^{2+}$ concentration $(2.0 \mu \mathrm{g} / \mathrm{L})$.
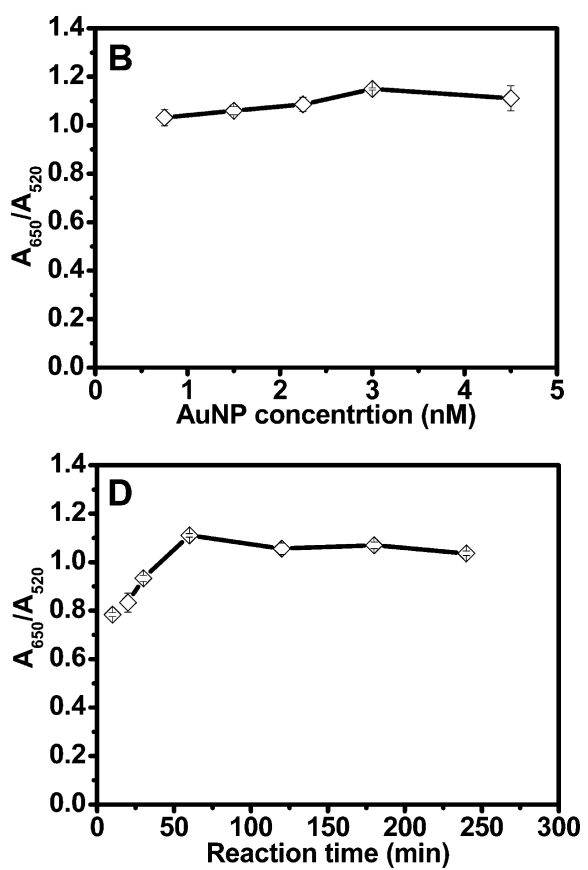

Figure 5. Optimization of chromogenic reaction conditions including pH of MPA-AuNPs solution (A), MPA-AuNPs concentration (B), reaction temperature (C), and reaction time (D). A volume of $600 \mathrm{~mL}$ of $2.0 \mu \mathrm{g} / \mathrm{L} \mathrm{Hg}^{2+}$ was extracted for $3 \mathrm{~h}$ at $250 \mathrm{rpm}$ under the optimized conditions of the donor, liquid membrane, and acceptor. 


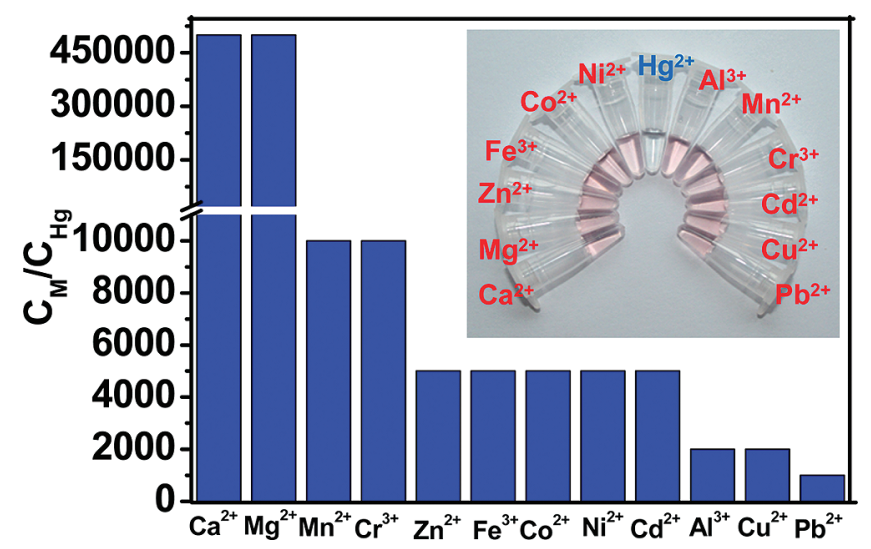

Figure 6. Tolerance to the interference of foreign heavy metals shown as the ratio of coexistent metals to $\mathrm{Hg}^{2+}\left(C_{\mathrm{M}} / C_{\mathrm{Hg}}\right)$ in the determination of $1.0 \mu \mathrm{g} / \mathrm{L} \mathrm{Hg}^{2+}$. Insert: photographic image of $1.0 \mu \mathrm{g} / \mathrm{L}$ coexisting ions and $\mathrm{Hg}^{2+}$ after treating by the proposed method.

Results shown in Figure 5B revealed that a relatively high $A_{650} /$ $A_{520}$ value was obtained at $3 \mathrm{nM}$ of MPA-AuNPs and was adopted in the subsequent studies.

Reaction Temperature and Time. The effect of temperature was studied with a constant reaction time of $1 \mathrm{~h}$. The result shown in Figure $5 \mathrm{C}$ indicates the $A_{650} / A_{520}$ value increased with temperature in the range of $20-30{ }^{\circ} \mathrm{C}$ due to the enhanced reaction rate. A further increase of temperature, however, gradually reduced the $A_{650} / A_{520}$ value which possibly is due to the slight disaggregation or precipitation of the aggregated MPAAuNPs. ${ }^{19}$ Figure 5D indicates that the time required to reach the steady state at $30{ }^{\circ} \mathrm{C}$ was $60 \mathrm{~min}$, which was adopted as the optimum.

Analytical Performance. The performance of the proposed method was evaluated based on the selectivity, sensitivity, and repeatability by using standard solutions.

Selectivity. Considering the high concentration of most foreign metal ions in comparison to that of $\mathrm{Hg}^{2+}$ in environmental water samples, it is of importance to study the specificity of the proposed method for $\mathrm{Hg}^{2+}$. The tolerance ratio of coexistent metals to $\mathrm{Hg}^{2+}\left(C_{\mathrm{M}} / C_{\mathrm{Hg}}\right)$ was determined by using solutions with a constant concentration of $\mathrm{Hg}^{2+}(1.0 \mu \mathrm{g} / \mathrm{L})$ and varied concentrations of foreign metal ions and adopting a criterion of $90-110 \%$ recovery of $\mathrm{Hg}^{2+}$ as noninterference. For all the studied metal ions including $\mathrm{Ca}^{2+}, \mathrm{Mg}^{2+}, \mathrm{Al}^{3+}, \mathrm{Fe}^{3+}, \mathrm{Co}^{2+}, \mathrm{Ni}^{2+}$, $\mathrm{Cu}^{2+}, \mathrm{Zn}^{2+}, \mathrm{Cr}^{3+}, \mathrm{Mn}^{2+}, \mathrm{Pb}^{2+}$, and $\mathrm{Cd}^{2+}$, the proposed procedure exhibited very high tolerance with $C_{\mathrm{M}} / C_{\mathrm{Hg}}$ values between 1000 and 500000 (Figure 6), suggesting this method is applicable for various environmental samples. At least two factors contribute to the extremely high selectivity toward $\mathrm{Hg}^{2+}$ : (i) PDCA, a very selective chelating ligand that has a stability constant with $\mathrm{Hg}^{2+}$ over 10 orders of magnitude higher than with other interfering metal ions, ${ }^{26}$ was used as a trapping agent in the HFSLM procedure; (ii) MPA, another complex reagent with about a 6 orders of magnitudes higher stability constant toward $\mathrm{Hg}^{2+}$ than with other interfering metal ions, ${ }^{26}$ was coated on the AuNPs for improve the selectivity in the colormetric detection procedure.

Sensitivity. Under the above optimized conditions, we evaluated the minimum concentration of $\mathrm{Hg}^{2+}$ detectable by the color change with the naked eye. Experiments showed that when the $600 \mathrm{~mL}$ samples was enriched in the HFSLM step, the test solution of the following chromogenic assay remained red for water samples containing $\leq 0.7 \mu \mathrm{g} / \mathrm{L} \mathrm{Hg}^{2+}$; for samples containing $\geq 0.8 \mu \mathrm{g} / \mathrm{L} \mathrm{Hg}^{2+}$, however, a distinct change of color from red to blue was observed by the naked eye. This result indicates that the proposed assay has a detection limit of $0.8 \mu \mathrm{g} / \mathrm{L} \mathrm{Hg}^{2+}$, which is the lowest one that has been reported for naked eye detection.

It is noteworthy that the detection limit was adjustable by varying the sample volume/extraction time in the HFSLM procedure. Considering the maximum level of mercury permitted by the U.S. EPA for drinking water is $2.0 \mu \mathrm{g} / \mathrm{L}$, we adjusted the conditions of the HFSLM procedure to meet this detection level. It was found that a detection limit of $2.0 \mu \mathrm{g} / \mathrm{L} \mathrm{Hg}^{2+}$ can be obtained by using a sample volume of $200 \mathrm{~mL}$ and extraction time of $3 \mathrm{~h}$ or a sample volume of $600 \mathrm{~mL}$ and extraction time of $1 \mathrm{~h}$. In both cases, a distinct color change from red to blue can be observed by naked eye when the $\mathrm{Hg}^{2+}$ concentration in the water samples increased from $1.8-2.0 \mu \mathrm{g} / \mathrm{L}$. Since a large volume of sample is readily available for environmental waters, we recommend use a sample volume of $600 \mathrm{~mL}$ and a extraction time of $1 \mathrm{~h}$ as optimum to improve the assay efficiency. The extremely high resolution $\left(0.1-0.2 \mu \mathrm{g} / \mathrm{L} \mathrm{Hg}^{2+}\right)$ with the naked eye in this proposed method was attributed to the high enrichment factor in the HFSLM (1000), which magnified the concentration difference to $100-200 \mu \mathrm{g} / \mathrm{L} \mathrm{Hg}^{2+}$ in the acceptor and thus can be distinguished with the naked eye-based visual detection.

Repeatability. The precision was evaluated by assaying five standard solutions with $2.0 \mu \mathrm{g} / \mathrm{L} \mathrm{Hg}^{2+}$. A clearly visible color changing was observed by the naked eye for all the five assays and determination of their $A_{650} / A_{520}$ values showed a relative standard deviation (RSD) of $2.4 \%$, demonstrating the excellent repeatability.

Real Sample Analysis. The applicability of the proposed method was evaluated by determination of $\mathrm{Hg}^{2+}$ in a certified reference water sample (GBW08603, $10 \mu \mathrm{g} / \mathrm{L} \mathrm{Hg}^{2+}$ ) and three real samples including tap water, river water, and lake water. The $\mathrm{Hg}^{2+}$ contents in the three real water samples were screened to be below the detection limit of the proposed visual assay method $\left(0.8 \mu \mathrm{g} / \mathrm{L} \mathrm{Hg}^{2+}\right.$, by enriching $600 \mathrm{~mL}$ samples with HFSLM for $3 \mathrm{~h})$, agreeing with the confirmed value $(<0.1$ $\mu \mathrm{g} / \mathrm{L} \mathrm{Hg}^{2+}$ ) by the atomic fluorescence spectrometer (AF610D2, Rayleigh, China). In order to further validate the method, each real water sample was spiked with $0,1.8$, and $2.0 \mu \mathrm{g} / \mathrm{L} \mathrm{Hg}^{2+}$, respectively; whereas the certified reference water sample was diluted with water to containing 1.8 and 2.0 $\mu \mathrm{g} / \mathrm{L} \mathrm{Hg}^{2+}$, respectively. These samples were detected under the general optimum conditions $(600 \mathrm{~mL}$ samples were enriched with HFSLM for $1 \mathrm{~h}$ ). Results shown in Figure 7 indicate that the color change can only be observed for samples containing $2.0 \mu \mathrm{g} / \mathrm{L} \mathrm{Hg}^{2+}$. This detection limit was identical with that obtained with standard solutions, demonstrating the reliability of the proposed method for analysis of real environmental water samples.

\section{CONCLUSIONS}

By coupling HFSLM preconcentration with MPA-AuNPs-based visual detection, an innovative visual assay procedure that meets 

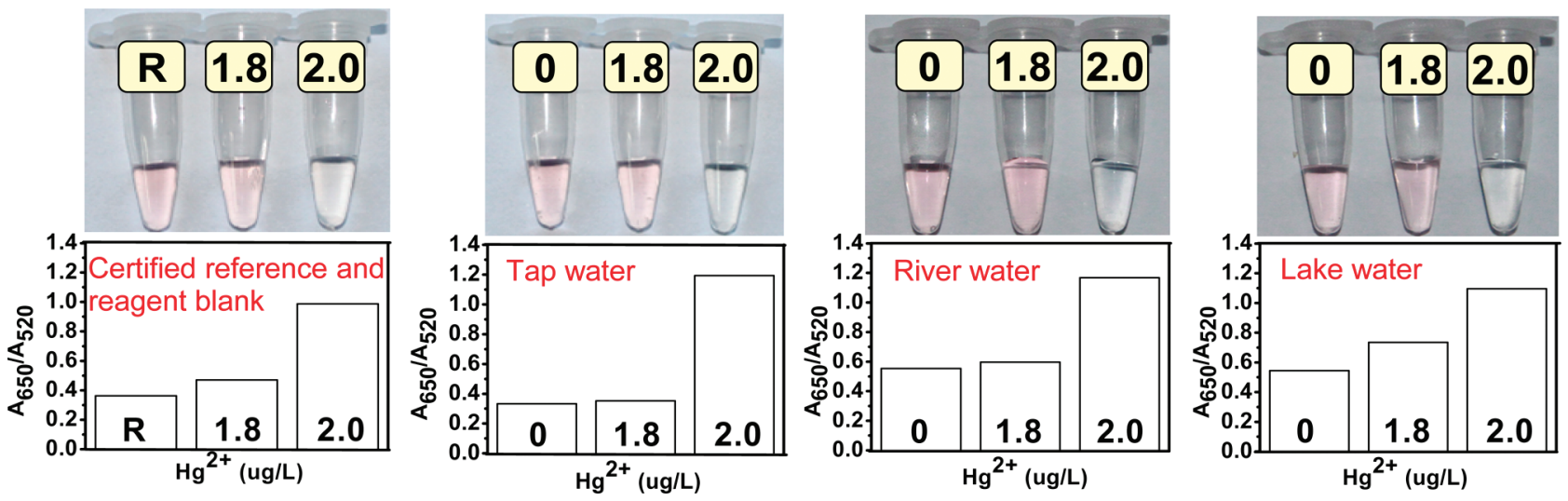

Figure 7. The absorbance ratio $\left(A_{650} / A_{520}\right)$ and photographic images of the certified reference water sample, tap water, river water, and lake water. The certified reference water sample was diluted to containing 1.8 and $2.0 \mu \mathrm{g} / \mathrm{L} \mathrm{Hg}^{2+}$, respectively. Each real water sample was spiked with $0,1.8$, and $2.0 \mu \mathrm{g} / \mathrm{L} \mathrm{Hg}^{2+}$, respectively. Sample solutions $(600 \mathrm{~mL})$ were extracted for $1 \mathrm{~h}$ at 250 rpm under the optimized conditions of donor, liquid membrane, and acceptor. $\mathrm{R}$ shows the reagent blank (mixture of ultrapure water, MPA-AuNPs, and Tris-borate buffer).

the EPA-desired $2.0 \mu \mathrm{g} / \mathrm{L}$ level with the naked eye was, for the first time, developed for accurate and rapid determination of $\mathrm{Hg}^{2+}$ in environmental waters. Because of the selectively high enrichment of $\mathrm{Hg}^{2+}$ by PDCA in the HFSLM procedure and the selective response to $\mathrm{Hg}^{2+}$ of the MPA functionalized AuNPs, the proposed method exhibited extremely high sensitivity and selectivity toward $\mathrm{Hg}^{2+}$. The high sensitivity of the proposed method allowed for visual analysis of $\mathrm{Hg}^{2+}$ down to the $2.0 \mu \mathrm{g} / \mathrm{L}$ safety level imposed by the EPA, while the simple facility required makes this procedure applicable for field analysis. Although this study had demonstrated the detection of $\mathrm{Hg}^{2+}$ ions only, significantly, this method can in principle be used to detect other metal ions, and such studies are being conducted in our laboratory.

\section{ACKNOWLEDGMENT}

This work was financially supported by the National Basic Research Program of China (Grant 2010CB933502) and the National Natural Science Foundation of China (Grants 20877082, 20921063).

\section{SUPPORTING INFORMATION AVAILABLE}

Additional information as noted in text. This material is available free of charge via the Internet at http://pubs.acs.org.

Received for review February 27, 2010. Accepted April 8, 2010.

\section{AC100541S}

